The Relation of Job Demands to Teacher and Staff Stress: Impact of a Job Crafting Intervention

\author{
Vissy Vandiya ${ }^{\mathrm{a}}$ and Arum Etikariena Hidayat ${ }^{\mathrm{b}}$
}

${ }^{a}$ Faculty of Psychology, Universitas Indonesia, Depok, Indonesia; ${ }^{b}$ Department of Industrial and Organizational Psychology, Faculty of Psychology, Universitas Indonesia, Depok, Indonesia

*Corresponding author:

Arum Etikariena Hidayat

Department of Industrial and Organizational Psychology

Faculty of Psychology, Universitas Indonesia

Depok, Jawa Barat, Indonesia

Email address: arum.etikariena@ui.ac.id / arum.hidayat@gmail.com 


\title{
The Relation of Job Demands to Teacher and Staff Stress: Impact of a Job Crafting Intervention
}

\begin{abstract}
Stress is something that cannot be avoided, especially stress related to one's work. Employees who experience job stress have been found to be less motivated and healthy, and, thus, less productive at work. The teachers and operational staff at the HIJ School confirmed that they felt job stress due to the unpredictable job demands of the school. The purpose of this study is to examine the relationship between job demands and job stress, and determine the appropriate interventions. Participants in this research included 56 teachers and staff who filled out an online questionnaire and who fit the following criteria: Indonesian citizens, minimum education level of a bachelor's degree, and a minimum of two years' work experience. The design of this research was quantitative and used Pearson correlation analysis using SPSS. The measuring tools used were the Job Stress Scale to measure job stress (DV) with Cronbach's alpha $=.86$, and the Challengeand-Hindrance-Related Self-Reported Stress Measures to measure job demands (IV) with Cronbach's alpha $=.90$. The respondents that took part in the intervention were six operational staff participating in a job crafting programme. The results of the research indicate that job demands significantly affect job stress $(\mathrm{p}<.05)$, and that job crafting interventions can decrease the perception of job demands with a pre-test/post-test difference of 38.33 and 31.00 respectively.
\end{abstract}

Keywords: job demands, job stress, job crafting programme, intervention

\section{Introduction}

\section{Background}

Employees who experience work stress tend to not be productive at work (Finney, Stergiopoulos, Hensel, Bonato \& Dewa, 2013). This is due to the emergence of psychological strains such as negative emotions, physiological stresses such as the appearance of physical problems, and behavioral strains such as decreased work performance (Liu, Liu, Mills \& Fan, 2013). Employees who experience work stress will adversely affect the organization due to health problems, decreased motivation, nonproductivity, and insecurities at work (Arshadi \& Damiri, 2013).

Stress cannot be avoided, be it due to traffic congestion, household affairs, high job demands, deadlines for completing work tasks, and changes that occur in the workplace (Lumbantobing, 2014). For a teacher, stress can be experienced at any stage of their career, in their work or classroom environment, due to student behavior, accountability for improving student performance, lack of resources, difficult parents, diverse needs for the student population, and a constantly changing teacher evaluation system (Clement, 2017).

Stress is the existence of something in the work environment that is perceived as a threat or demand that causes employees to feel uncomfortable (Bell, Rajendran \& Theiler, 2012). Job stress is psychological distress that arises from individual and organizational stressors at work 
(Finney et al., 2013). The factors that cause stress can arise from: individual factors, such as family and partner problems, or financial problems, (Aamodt, 2016); job factors, such as role conflict, role ambiguity, and role overload (Affrunti, Mehta, Rusch \& Frazier, 2018); organizational factors, such as the person-organization fit (i.e., how good or suitable skills, knowledge, abilities, expectations, personality, values and personality of the employee fit with the organization), organizational rules and policies, relationships with superiors and organizational changes (Arden, 2002); and work environment factors, such as noise and room temperature (Aamodt, 2016). Another factor that can affect job stress is the high job demands that are not in accordance with existing resources, or do not meet the needs and motivations of an individual (Stranks, 2005). Thus, job demands are a source of stress that comes from the organization (Robbins \& Judge, 2015)

Job demands are physical, social and organizational aspects of a job that require continuous effort (Affrunti et al., 2018). Job demands consist of quantitative and qualitative demands. Quantitative demands are about the amount of work, workload, and the required speed in carrying out tasks, whereas qualitative demands are about the type of skill or effort needed to perform work tasks, namely cognitive, physical and emotional skills. Thus, qualitative demands are related to the level of difficulty or complexity of the work (Peeters, Jonge \& Taris, 2014). Employees who have high job demands will be exhausted because of the many physical and psychological resources that are depleted, making employees have less energy (Simbula, 2010). For a teacher, one of the job demands is family conflict in that teachers must prepare teaching materials and examinations for the next day at home and have to sacrifice family time (Simbula, 2010).

Both employees and teachers who experience high job demands will experience job stress. The study of this issue is very important because it will negatively affect the organization if it is not addressed. Based on this, the aim of the present research is to examine job demands and job stress which were a problem in HIJ schools.

HIJ School is a private school using the International Baccalaureate (IB) curriculum and part of the corporate HIJ foundation. HIJ schools accept children from preschool to high school. Based on the IB curriculum, the year groups in the HIJ School are split up into three categories: Primary Years Program, consisting of the play group (Early Years 1/EY1), kindergarten (Early Years 23/EY 2-3) and grades one to five elementary schools (Elementary/EL 1-5); the Middle Years Program (MYP), consisting of elementary school grades six through to high school grade one (MYP Gr. 6-10); and finally the Diploma Program (DP), consisting of grades two to three in high school (DP Gr. 11-12).

The current number of teachers and operational staff of HIJ schools are 184 people, consisting of 119 citizens and 65 foreigners. There are 119 Indonesian citizens: 78 teachers, five counselors, 33 operational staff, and three management personnel. The present study only takes into account Indonesian citizens because foreigners, due to their contractual employment status, were assumed to eventually move to other organizations or return to their country at the end of their contract. In addition to the three management personnel, five operational staff were not 
included in the study because they were outsourced staff. Thus, the current study focused on 111 citizens.

The phenomenon that occurs in HIJ schools is there is an inconsistency with the application of rules and regulations; in other words, job demands cannot be predicted and anticipated by teachers and staff. Every year, teachers and staff do not know how their work will change and what additional work is required of them which inevitably causes undue stress for teachers and staff. The author took observational data from teachers as one of the members of the organization Focus Group Discussion (FGD). No operational staff attended the FGD because there were still jobs they had to attend to.

One example of job demands experienced by teachers at HIJ schools include elementary level (PYP) teachers who have received additional teaching classes, namely teaching junior high school level (MYP) classes. This means they have two different heads, have different demands and performance appraisals, and have had to receive additional teaching at MYP because of the large number of students taking certain subjects at a MYP level despite lacking teachers for the subjects. This also applies to MYP subject teachers who also teach for high school level (DP). However, the teachers did not receive salary increases, and it was only acknowledged as an added value in their performance appraisals. The additional tasks for operational staff was the obligation of students to use a blazer or vest, and operational staff were given the task of managing the fitting and distribution for each student. These were also coupled with the existence of ID cards for parents, called parent cards, which the management asked the operational staff to take care of: from data collection of the parents' names of all HIJ school students, to the parent card distribution. Examples of job demands were included in quantitative demands due to the increased workloads and the speed needed to do these tasks (e.g., assessing student assignments, data administration, and making the timetable).

In addition to the quantitative demands felt by teachers and staff, they also felt cognitive demands such as teachers having to master the taught subjects, especially subject teachers who teach more than one level of education (those who teach PYP-MYP and MYP-DP classes), and operational staff who have to possess the knowledge and skills to run computer programs and communicate in English. Physical demands were also felt by teachers and staff, for example lab assistants who have to always prepare chemicals for teaching purposes that can be harmful to the body, as well as staff who always work at the computer in the same sitting position for nine hours. Emotional demands were also felt by teachers and staff such as always having to show positive emotions to students (especially PYP students), and to parents in the case of operational staff.

Many changes in rules and job demands were also found to be inconsistent in HIJ schools. Constantly increasing the tasks that must be performed made teachers and staff often feel anxious, frustrated, and stressed. If this was not immediately addressed, teachers and staff who experienced ongoing job stress could have an adverse impact on the organization. Symptoms of job stress consist of physical symptoms (such as headaches, back pain, no appetite, overeating, strained shoulders, diarrhea, insomnia, flu symptoms), psychological symptoms (such as 
pessimism, forgetfulness, boredom, impatience, depression, restlessness, desire to leave the organization), and behavioral symptoms (anxiety, irritability, aggressiveness, suspicion, absenteeism) (Arden, 2002). The symptoms of job stress felt by teachers and operational staff from the results of informal interviews with several teachers and staff were the increasing frequency of headaches, digestive problems, cold sweat, changes in the schedule of staging, mood changes at work, lack of appetite, and forgetfulness. Based on informal interviews with HIJ school clinic nurses, most complaints from teachers and staff attending the clinic were headaches, muscle or joint pains, and flu symptoms.

The aim of this study is to focus on job demands as independent variables and job stress as dependent variables. By examining the relationship between work demands and stress, a suitable intervention could be tested so that HIJ School teachers and staff could possibly reduce their job demands, as well as study whether decreasing job demands also decreased stress.

\section{Formulation of Problems, Objectives, and Benefits of Research}

Based on the background and organizational problems at HIJ schools, the formulation of the problem for this study is:

- Does a relationship between job demands and job stress exist?

- What suitable interventions exist to reduce the perception of job demands that could reduce teacher and staff stress in the HIJ School?

- Was there any significant difference in the perception of job demands after teachers and staff partook in the intervention?

The expected benefits of this research were with the right intervention, teachers and staff could carry out their work better because, if job demands cause job stress, it could potentially decrease stress, and teachers and staff could work more optimally and productively which would benefit HIJ schools.

\section{Literature Review}

\section{Job Stress}

Robbins and Judge (2015) define stress as an adaptive response to situations that are considered challenging or threatening to the welfare of individuals. According to Bell et al. (2012), job stress is something in the work environment that is perceived as a threat or demand, or a situation in the workplace that causes discomfort in employees. Job stress is also defined as a dangerous physical and psychological response that occurs when work is not in accordance with the capabilities, resources, and needs of employees (Ikonne, 2015; Shukla \& Srivastava, 2016)

Stress has two types, positive stress (eustress) and negative stress (distress), and their impact depends on the individual. Negative stress or distress is a deviation in behavior, both physical and psychological which can reduce health and work performance (Aamodt, 2013). Positive stress or eustress will motivate individuals to achieve their goals, make them able to change their environment, and succeed in facing life's challenges (Robbins \& Judge, 2015). Eustress has been found to improve health and work performance (Aamodt, 2013). Because individual 
stress is subjective, two individuals who experience stress due to work pressure can experience it completely differently with one individual experiencing eustress and the other distress.

Ogden (2007) mentions stress differentiation, namely acute stress and chronic stress. Acute stress is an event that only lasts for a while although its impact lasts a long time (Koslowsky, 1998) such as having to do a presentation in front of other colleagues. Chronic stress is an event that occurs in everyday life which is often referred to as 'daily hassles' which are disturbing (Koslowsky, 1998) such as job stress.

Stress causes symptoms in the individual body. Robbins and Judge (2015) divide these symptoms into three categories: (1) Physiological Symptoms: emerging symptoms that affect body health, especially when experiencing severe chronic stress; (2) Psychological Symptoms: anxiety, tension, boredom, and procrastination. Individuals who have external locus of control, with increasing job control, will also increase stress and fatigue; (3) Behavioral Symptoms: decreased productivity, absenteeism, turnover, changes in diet, talking faster, anxiety, and sleep disturbances.

Individuals who experience stress are not the only ones affected; the organization or company where the individual works is affected also. According to Aamodt (2013), the impact or consequences of stress consists of (1) Personal Impact: starting or increasing the frequency of smoking, alcohol, or even illegal drugs, as well as the appearance of severe diseases such as heart disease and strokes that can cause death; and (2) Organizational Impact: decreased job performance, burnout (i.e., when an individual is overwhelmed with very high job demands that are too stressful), decreased productivity, absenteeism, and turnover.

According to Robbins and Judge (2015), the source of stress (stressors) is divided into three parts: environment, organization, and personal. Thus, job demands is a factor that contributes to employee stress.

\section{Job Demands}

Job demands are physical, psychological, social and organizational aspects of work that require ongoing physical and/or psychological efforts and, therefore, are associated with certain psychological and/or physical costs (Bakker \& Demerouti, 2014), as well as fatigue and cynicism (Broeck, Cuyper \& Witte, 2010). According to Lee, Shin, and Baek, (2017), job demands include excessive workload (work overload), emotional demands, and technological demands.

Job demands are divided into two subcategories: (1) Job Hindrance, a job demand that is a barrier and can damage the health of individuals. Employees who experience job hindrance will feel negative emotions, so they tend to adopt emotionally-focused coping (Broeck et al., 2010); (2) Job challenges, job demands that require energy but still stimulate and have potential advantages as well as curiosity, competence, and accuracy of employees. Employees who experience job challenges will use problem-focused coping, so they tend to contribute to the achievement of work goals (Broeck et al., 2010). 
Job demands are influenced by employees' perceptions of their work environment, so for example, employees who experience stress will evaluate job demands more critically, and complain more often about their workload and create a negative work environment (Broeck et $a l ., 2010)$. Broeck et al., (2010) explain that job demands (such as work pressure and emotional demands) are the most important antecedents of acute fatigue due to prolonged stress and will predict employee performance.

Job demands and interacting resources in predicting work well-being have an indirect impact on job performance (Broeck et al., 2010). Employees who experience job demands can impact the organization due to health problems caused by fatigue and prolonged stress, or the desire to resign (De Beer, Rothmann \& Pienaar, 2012). Physical job demands can cause stress due to environmental factors, cognitive job demands due to uncertainty felt in the workplace, and emotional job demands because they must show emotions that are not actually felt (Peeters $e t$ al., 2014).

The impact of job demands that cause stress must be addressed immediately because they are detrimental to teachers and staff and will ultimately harm the organization. At HIJ School, the intervention that the authors used to reduce high job demand was job crafting.

\section{Intervention - Job Crafting}

Broeck et al., (2010) describe one possible intervention for Job Demands-Resources (JD-R) as job crafting. Job crafting can compensate employees for the demands of their work and work resources by focusing on their personal abilities and needs (Peeters et al., 2014). Job crafting is an individual-level intervention initiated by employees by which they change their work informally so that it is more in line with their interests and skills (Aamodt, 2013). Broeck et al., (2010) stated that job crafting is a cognitive and physical change that is done by individuals in their tasks or relational boundaries. Physical change refers to changes in shape, scope, and number of tasks, while cognitive change refers to changes in individual perceptions of their work.

There are three types of job crafting: (1) Task crafting, changing the scope or nature of the tasks faced today and the ability to take on additional tasks; (2) Relational crafting, changing the nature and level of relationships with others and the ability to create new relationship; and (3) Cognitive crafting, to change perceptions or redefine the type or nature of one's tasks and involvement with work to be more positive (Berg, Dutton \& Wrzesniewski, 2008).

Job crafting was chosen as an intervention in this study because it was considered suitable for the purposes of the current study: to change the perception of teachers and staff about the job demands they were facing so that they could overcome job demands and reduce stress. Job crafting was new to teachers and staff; therefore, it was presented as an introductory program. 
The research framework was as follows:

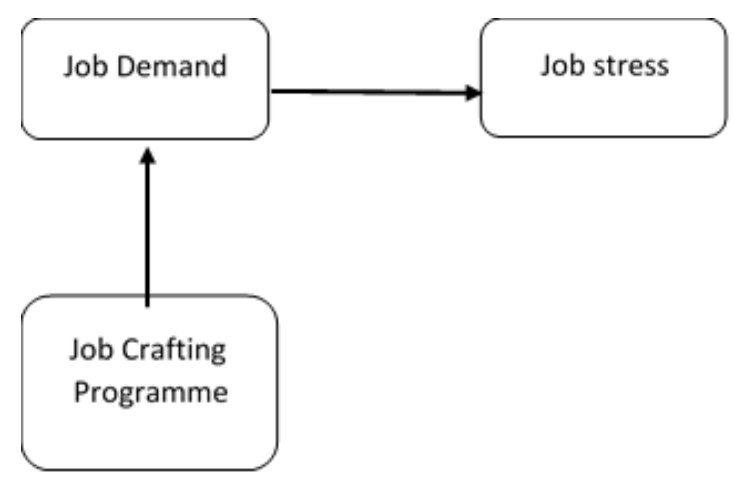

Fig. 1. Research Framework

\section{Methods}

The research method used in the current research were quantitative methods in applied research, namely techniques, procedures, and research methods applied to data collection in various situations, problems, or phenomena so that information can be used to improve understanding of the phenomenon (Kumar, 2005). According to Pedhazur and Schmelkin (1991), applied research is research that aims to solve practical problems. In terms of its objectives, this study was correlational research that was to find or establish the relationship between two or more aspects of the existing situation (Kumar, 2005) using the Pearson correlation coefficient. To test the relationship between the two variables, the variable job demands were identified as IV and the job stress variable as DV.

The respondents selected for this study were unknown and had an unspecified choice probability, i.e., nonprobability sampling by convenience sampling method. Respondents for this study were divided into FGDs, surveys, and interventions. FGD respondents were four teachers: one PYP classroom teacher, one PYP teaching teacher, and two MYP-DP teaching teachers. Survey respondents were 56 teachers and staff with a response rate of $50.45 \%$. Respondents included six operational staff. The criteria for respondents were: (1) Teachers and HIJ school operational staff, (2) Indonesian citizens, (3) Undergraduate (bachelor's degree) holders, (4) Aged 25-55 years old, (5) Had at least two years of work experience in HIJ schools. The research measuring instrument used for job stress was the Job Stress Scale measure developed by Shukla and Srivastava (2016) which consists of four dimensions: job stress scale (nine items), role expectation conflict (five items), coworker support (four items), and work-life balance (four items). The scale used six-point Likert scales ranging from: 1 Strongly Disagree, 2 Disagree, 3 Rather Disagree, 4 Rather Agree, 5 Agree, and 6 Strongly Agree. The three dimensions tested were job stress scale, role expectation conflict, and work-life balance. For the coworker support dimension, a six-point Likert scale was used consisting of 1 Never, 2 Very Occasionally, 3 Sometimes, 4 Often, 5 Very Often, and 6 All the Time.

The measuring instrument used to measure job demands was the Challenge-and-HindranceRelated Self-Reported Stress Measures, developed by Cavanaugh, Boswell, Roehling, and 
Boudreau (2000). The dimensions of the work demands consist of two dimensions: challenge stressor (six items) and hindrance stressor (five items). The scale used was a five-point Likert scale from 1 (produces no stress) to 5 (produces a great deal of stress).

\section{Results}

\section{Results of Analysis}

Out of the 111 respondents, 56 filled out the survey. The participants' demographic data is included in Table 1.

Table I. Demographic Data

\begin{tabular}{llll}
\hline \multicolumn{1}{c}{ Category } & \multicolumn{1}{c}{ Information } & Total & Percentage \\
\hline \multirow{2}{*}{ Gender } & Male & 19 & $34 \%$ \\
Age & Female & 37 & $66 \%$ \\
\multirow{5}{*}{ Last Education } & $16-36$ & 25 & $45 \%$ \\
\multirow{3}{*}{ Working Experiences } & $37-59$ & 31 & $55 \%$ \\
& Bachelor & 35 & $63 \%$ \\
& Master & 21 & $38 \%$ \\
& $1-4$ years & 6 & $11 \%$ \\
& 9 years and more & 11 & $20 \%$ \\
& PYP Class \& Ass. & 6 & $69 \%$ \\
& Teacher & 6 & $11 \%$ \\
Department & PYP Subject Teacher & 6 & $11 \%$ \\
& MYP-DP Subject & 18 & $32 \%$ \\
& Teacher & & \\
& PYP-MYP Subject & 7 & $13 \%$ \\
& Teacher (Religion) & & \\
& Operational Staff & 14 & $25 \%$ \\
& Counselling & 5 & $9 \%$ \\
\hline
\end{tabular}

The results of the validity and reliability test for measuring job demands was $n=56$ and $r$ table value $=.22$ with a $95 \%$ significance level, and .31 for a $99 \%$ significance level, indicating that all the items were valid because they were $>.31$. The Cronbach's Alpha value for measuring job demand was .90. According to Kaplan and Saccuzzo (2009), the reliability value of a measuring instrument between .70 and .80 makes the measuring instrument good enough for basic research. Based on the results of the data analysis of the job demands, the total mean value was 31.52 , and $61 \%$ of teachers and staff felt a high job demand.

Based on the variable division of job demands per dimension, namely the dimensions of the challenge stressors and hindrance stressors, the total mean values for dimension challenge stressors were $=16.70$ and hindrance stressors $=14.82$. Teachers and staff who felt high challenge stressors and hindrance stressors were $59 \%$.

In the challenge stressors dimension, the highest number of challenge stressors were found in operational staff (31\%) and MYP-DP subject teachers (30\%), female participants (76\%), 
participants aged 37-59 years old (52\%), those with a bachelor's degree (73\%), and participants who had nine years or more of work experience $(64 \%)$.

In the hindrance stressors dimension, the participants who experienced the highest level of stressors were operational staff (31\%), MYP-DP subject teachers (30\%), female participants $(61 \%)$, participants aged 37-59 years old (61\%), those with a bachelor's degree $(67 \%)$, and participants who had nine years or more of work experience $(70 \%)$.

This showed that teachers and staff at HIJ schools experienced high job demands in the challenge and hindrance area.

Based on the results of the job stress variable data analysis, the Cronbach's Alpha value for the job stress measuring instrument was .86, so the instrument was reliable. Based on the results of the analysis, the total mean value was 57.29 and $46 \%$ of teachers and staff were found to have felt high job stress.

Based on the division of job stress variables in four dimensions (job stress scale, role expectation conflict, work/life balance and co-worker support), the mean value of each dimension was 23.38 for the job stress scale dimension, 13.14 for the dimension of role expectation conflict, 10.93 for the dimension of work/life balance, and 9.84 for the dimension of co-worker support. Participants who scored high on the Job Stress Scale (JSC) made up 46\% of the group, which included operational staff (31\%), MYP-DP subject teachers (31\%), female participants (62\%), participants aged 37-59 years old (54\%), those with a bachelor's degree (65\%), and participants who had nine years or more of work experience $(65 \%)$.

In the role expectation conflict dimension, $43 \%$ of participants were found to score high on the role expectation conflict (REC) with the highest number of these being operational staff (34\%), MYP-DP subject teachers (33\%), female participants (54\%), participants aged 16-36 years old $(50 \%)$, participants aged $37-59$ years old $(50 \%)$, those with a bachelor's degree $(71 \%)$, and participants who had nine years or more of work experience $(67 \%)$.

In the dimensions of life balance, the groups of participants who experienced the lowest work/life balance (WB) were $45 \%$ of MYP-DP subject teachers (36\%), female participants $(68 \%)$, participants aged 37-59 years old (68\%), those with a bachelor's degree (52\%), and participants who had nine years or more of work experience $(72 \%)$.

In the dimensions of co-worker support (CWS), the groups of participants who experienced the lowest support from their co-workers were 52\% of MYP-DP subject teachers (31\%), female participants (62\%), participants aged 37-59 years old (59\%), those with a bachelor's degree (52 $\%)$, and participants who had nine years or more of work experience $(69 \%)$.

Based on the results from the data analysis for job demands and job stress variables, not all the teachers and staff who experienced high job demands were found to experience high job stress. The quantity of teachers and staff who felt high job demands and job stress were 23 people, the 
highest of which were nine people that were operational staff (39\%). Teachers and staff who experienced the highest job demands and high job stress were women (65\%), those with a bachelor's degree (74\%), and participants who had nine years or more of work experience $(61 \%)$.

The results of the correlation analysis showed that the variables of job demands and job stress had a significant relationship with a significance value of .00 ( $\mathrm{p}<.05)$. The job demands (JD) variables had two dimensions: challenge stressors (CS) and hindrance stressors (HS). The job stress variables (JS) had four dimensions: job stress scale (JSC), role expectation conflict (REC), work life balance (WB), and co-worker support (CWS).

The results from the matrix correlation analysis between the variables and dimensions showed that the highest value was the job stress scale (JSC) dimension with the challenge stressors (CS) dimension, with a correlation value of .65 and $\operatorname{sig}=.00(\mathrm{p}<.01,2$-tailed $)$. This shows that HIJ teachers and school staff needed attention to what challenge/s in their work related to the job stress scales. In the job stress scale dimension, some of the statements were (1) my work makes me anxious; (2) I feel worried because I have a lot of work, but the finishing time is very short; and (3) Often, my work becomes a heavy burden. Whereas in the dimensions measuring the challenge stressors some of the statements were (1) the number of responsibilities that I have, (2) the time pressure I have, and (3) the amount of work that must be completed in a certain time.

Table II. Matrix Correlation Analysis Result

\begin{tabular}{lllll}
\hline \multirow{2}{*}{ No } & \multirow{2}{*}{ Variable } & \multirow{2}{*}{ Dimension } & \multicolumn{2}{c}{ Job Demand } \\
\cline { 3 - 4 } & & CS & HS \\
\hline 1 & & JSC & $.65^{* *}$ & $.51^{* *}$ \\
2 & Job Stress & $.46^{* *}$ & $.45^{* *}$ \\
3 & WEC & $.56^{* *}$ & $.56^{* *}$ \\
4 & & WB & $.37^{* *}$ & $.55^{* *}$ \\
\hline \multicolumn{4}{c}{ CWS } & Note: $\mathrm{N}=56, * * \mathrm{p}<.01$
\end{tabular}

\section{Intervention Program - Job Crafting Introduction Program}

Based on the results indicating that $61 \%$ of teachers and staff experienced high job demands according to the job demands variable, the authors intervened to attempt to reduce the job demands.

The intervention chosen was an introductory program regarding job crafting, and it was necessary to introduce the theory of job crafting, as well as the training to do job crafting before applying it at the workplace. The introduction of job crafting was done over two days, then the respondents were given two weeks to apply the job crafting to their work.

The introduction program on job crafting consisted of three parts: (1) implementation of the introduction program, (2) The application of the job crafting knowledge in participant's working lives, and (3) evaluation through monitoring by respective superiors, as well as a post-test to see if there were any changes after attending the program. 
The implementation of this intervention lasted for two days from 3:00 p.m. - 5:30 p.m. On the first day, the researcher as the facilitator explained the theories about job crafting and discussed the tasks for each individual based on their job description (and outside the job description), as well as the obstacles and tasks that they were handling well. This served as an illustration for respondents about how their tasks needed to be redesigned. On the second day, the respondents practiced redesigning the characteristics of their tasks, and the last session ended with wrap-ups and evaluations which discussed the results of job crafting and feedback for the intervention activities. In this last activity the facilitator explained three forms of job crafting that participants could do, namely task crafting, relational crafting, and cognitive crafting. Additionally, the facilitator explained the risks that might occur during the implementation of this job crafting and respondents were expected to be able to discuss these with their superiors.

After the intervention, a post-test was conducted two weeks after to examine whether there had been any changes. Based on the results of the non-parametric analysis of the Wilcoxon Signed Ranks Test, the difference in values between the pre-test and post-test showed a significant influence of the application of job crafting on job demands (sig value <.05). In other words, the perception of the six operational staff's job demands decreased and it was expected that their job stress would decrease also. Job stress was not counted in the post-test because job stress cannot be known directly and requires longitudinal testing. Therefore, job stress will be measured after the intervention program by respondents' respective superiors.

Table 3 summarizes the results of the differences between the pre-test and post-test.

Table III.The Result of Pre-Test and Post-Test

\begin{tabular}{cccc}
\hline Definition & Mean & SD & $\begin{array}{c}\text { Asymp. Sig (2- } \\
\text { tailed) }\end{array}$ \\
\hline Pre-Test & 38.33 & 4.50 & .03 \\
Post-Test & 31.00 & 4.86 & .03 \\
\hline
\end{tabular}

\section{Discussion, Conclusion, and Recommendation}

\section{Discussion}

Not all teachers and staff who experience high job demands experienced high stress. Although $61 \%$ of teachers and staff experienced high job demands, only $46 \%$ experienced job stress. The number of teachers and staff who experienced high job demands and job stress were 23 out of 56 people, most of which were operational staff.

In this study, some findings to highlight were the number of teachers and staff who experienced high job demands but did not necessarily feel stressed. Interventions were carried out based on the most problematic dimensions. In the case of job stress variables, the most problematic dimensions were the dimension of co-worker support with as many as $52 \%$ of participants feeling low support from co-workers, and the dimensions of job demands such as challenge and 
hindrance of which $59 \%$ of participants experienced a high challenge stressor and hindrance stressor.

In this study, the intervention was carried out based on the results of data analysis which showed the value of job demands and high job stress which were not based on dimensions. Interventions could be more focused based on the analysis of each specific dimension so that the program can be used in accordance with the problems faced by teachers and staff at HIJ School. After that, it was necessary to periodically monitor the supervisors for one, three and six months, respectively, to see if there were any changes that the operational staff experienced after implementing job crafting.

\section{Conclusion}

The conclusions of this study are as follows:

- A relationship between job demands and job stress was found with a significance value of $p$ $<.05$.

- Job crafting was found to be a suitable intervention to reduce the perception of job demands and which was expected to decrease job stress in the HIJ school. Before carrying out job crafting, it was necessary to be equipped with the proper knowledge about job crafting by explaining its underpinning theories so it could be applied to participants' working lives.

- Based on the results of the comparison between the pre-test and post-test, there was a decrease in the value of job demands after the job crafting intervention, which was 38.33 to 31.00 respectively.

\section{Recommendation for Future Research}

Measuring job demands can be reconsidered, especially based on the scales. The scale for the challenge stressor dimension could be changed starting from scale 1 Not Challenging, to scale 5 Very Challenging. This is to fit the goal of the challenge stressor, which measures how far individuals are challenged and motivated by their work. This is also the case with the hindrance stressor dimension which could be changed from scale 1 Not Obstructing, to scale 5 Very Obstructing.

Based on the intervention conducted by researchers at HIJ school on operational staff, the intervention was carried out with an introduction program on job crafting using flexible tasks. Management also needs to include job crafting as a method of discussion, especially for new teachers and staff so they are ready to anticipate these conditions. Thus, the teachers and staff can continue to develop themselves by practicing job crafting in their working lives.

Job crafting programs can be made based on the problems faced by each situation and so can differ depending on the results of the research, which dimensions were the most problematic, and what problems are faced by each department because the job demands felt by each department are different. 


\section{References}

Aamodt, M. G. (2013). Applying psychology to work ( $7^{\text {th }}$ ed.). Boston, MA: Wadswoth Cengage Learning

Aamodt, M. G. (2016). Industrial/organizational psychology: An applied approach (eighth edn.). Boston, MA: Cengage Learning.

Affrunti, N. W., Mehta, T., Rusch, D., \& Frazier, S. (2018). Job demands, resources, and stress among staff in after school programs: Neighborhood characteristics influence associations in the job demands-resources model. Children and Youth Services Review, 88, 366-374. doi: 10.1016/j.childyouth.2018.03.031.

Arden, J. B. (2002). Surviving job stress: how to overcome workday pressures. NJ: Career Press.

Arshadi, N., \& Damiri, H. (2013). The relationship of job stress with turnover intention and job performance: Moderating role of OBSE. Procedia-Social and Behavioral Sciences, 84, 706-710. doi: 10.1016/j.sbspro.2013.06.631.

Bakker, A. B., \& Demerouti, E. (2014). Job demands-resources theory. Wellbeing: A complete reference guide (Volume III), 1-28.

Bell, A. S., Rajendran, D., \& Theiler, S. (2012). Job Stress, Wellbeing, Work-Life Balance and Work-Life Conflict Among Australian Academics. E-Journal of Applied Psychology, 8(1), 25-37.

Berg, J. M., Dutton, J. E., \& Wrzesniewski, A. (2008). What is job crafting and why does it matter? Regents of the University of Michigan.

Cavanaugh, M. A., Boswell, W. R., Roehling, M. V., \& Boudreau, J. W. (2000). An empirical examination of self-reported work stress among US managers. Journal of applied psychology, 85(1), 65-74. doi: 10.1037/0021-9010.85.1.65. PubMed: 10740957.

Clement, M. (2017). Why Combatting Teachers' Stress is Everyone's Job. The Clearing House: A Journal of Educational Strategies, Issues and Ideas, 90(4), 135-138. doi: 10.1080/00098655.2017.1323519.

De Beer, L., Rothmann Jr, S., \& Pienaar, J. (2012). A confirmatory investigation of a job demands-resources model using a categorical estimator. Psychological Reports, 111(2), 528-544. doi: 10.2466/01.03.10.PR0.111.5.528-544.

Finney, C., Stergiopoulos, E., Hensel, J., Bonato, S., \& Dewa, C. S. (2013). Organizational stressors associated with job stress and burnout in correctional officers: a systematic review. BMC public health, 13(1), 82. doi: 10.1186/1471-2458-13-82. PubMed: 23356379.

Ikonne, C. N. (2015). Job stress and psychological well-being among library employees: a survey of library staff in selected university libraries in South-West Nigeria. Open Access Library Journal, 2(e1632), 1-12.

Kaplan, R. M., \& Saccuzzo, D. P. (2009). Psychological testing: principles, applications, and issues (7 (th $^{\text {th }}$ ). Belmont, CA: Wadsworth Cengage Learning.

Koslowsky, M. (1998). Modeling the stress-strain relationship in work setting. London: Routledge.

Kumar, R. (2005). Research methodology: A step-by-step guide for beginners ( $2^{\text {nd }}$ ed.). London: SAGE Publications.

Lee, S. H., Shin, Y., \& Baek, S. I. (2017). The impact of job demands and resources on job crafting. Journal of Applied Business Research (JABR), 33(4), 829-842.

Liu, C., Liu, Y., Mills, M. J., \& Fan, J. (2013). Job stressors, job performance, job dedication, and the moderating effect of conscientiousness: A mixed-method approach. International Journal of Stress Management, 20(4), 336 -363. doi: 10.1037/a0034841.

Lumbantobing, L. R. (2014). Stres di tempat kerja. Retrieved from Badan Pendidikan dan Pelatihan Keuangan Kementerian Keuangan. Retrieved from http://www.bppk.kemenkeu.go.id/id/publikasi/artikel/150artikel-keuangan-umum/20279-stres-di-tempat-kerja.

Ogden, J. (2007). Health psychology (4 ${ }^{\text {th }}$ edn.). Berkshire: McGraw-Hill Education.

Pedhazur, E. J., \& Schmelkin, L. P. (1991). Measurement, design, and analysis: an integrated approach. Hillsdale, NJ: Lawrence Erlbaum Associates.

Peeters, M. C., Jonge, J. D., \& Taris, T. W. (2014). An introduction to contemporary work psychology. Chichester, West Sussex, UK: Wiley Blackwell.

Robbins, S. P., \& Judge, T. A. (2015). Organizational behavior - global edition (16 ${ }^{\text {th }}$ edn.). New York: Pearson. 
Shukla, A., \& Srivastava, R. (2016). Development of short questionnaire to measure an extended set of role expectation conflict, coworker support and work-life balance: The new job stress scale. Cogent business \& management, 3(1), 1. doi: 10.1080/23311975.2015.1134034.

Simbula, S. (2010). Daily fluctuations in teachers' well-being: A diary study using the Job Demands-Resources model. Anxiety, Stress, \& Coping, 23(5), 563-584.

Stranks, J. (2005). Stress at work, manajemen and prevention. Burlington, MA: Elsevier Butterworth-Heinemann.

Van den Broeck, A., De Cuyper, N., De Witte, H., \& Vansteenkiste, M. (2010). Not all job demands are equal: differentiating job hindrances and job challenges in the Job Demands-Resources model. European Journal of Work and Organizational Psychology, 19(6), 735-759. doi: 10.1080/13594320903223839. 